\title{
Trends and Causes of Maternal Mortality at the Wa Regional Hospital, Ghana: 2005-2010
}

\author{
Sylvester Z. Galaa \\ Department of Social, Political and Historical Studies, University for Development Studies, Wa Campus \\ sylvestergalaa@yahoo.com
}

\section{Umar Haruna and Gordon Dandeebo}

Department of Social, Political and Historical Studies, University for Development Studies, Wa Campus DOI//http://dx.doi.org/10.4314/gjds.v13i1.5

\begin{abstract}
Maternal mortality has been a health concern for many developing countries. The study undertook a comprehensive maternal mortality audit at the Wa Regional Hospital in order to discover the trends and causes of maternal mortality at the hospital, and suggest ways of improving the situation. The study involved a retrospective examination of maternal mortality cases from January 1, 2005 to December 31, 2010. It included all pregnancy related deaths at the hospital within this period. A gynecologist and midwives served as key informants who provided primary data to augment the secondary data collected. Results showed a total of 73 maternal deaths occurred out of 14027 live births, giving a maternal mortality ratio of 520.4 per 100,000 live births. The yearly maternal mortality ratios saw an undulating scenario. On the specific causes of death, direct causes accounted for 60\%, while indirect causes were 40\%. Medically, haemorrhage (19\%), Eclampsia (15\%), Sepsis (11\%), abortion related difficulties (8\%) and obstructed labour (7\%) were the main causes of mortality. Indirect causes include malaria, aneamia, sickle cell, HIV-Aids and TB. The trends of maternal mortality in the Upper West Regional Hospital over the period have seen a decline, but the decline is not significant enough. The number of women still dying from trying to bring life is unacceptably high. Key recommendations include the need to: improve emergency obstetric care by ensuring that there are enough personnel, logistics and facilities to attend to women who are in labour, especially 12 hours prior to delivery and after delivery.
\end{abstract}

Keywords: Maternal Mortality, Maternal Mortality Ratio, Trends, Wa Regional Hospital, Ghana 


\section{Background of the Study}

According to Prof. F. T Sai, "No nation sends its troops to war without guaranteeing their safe return, however for generations, men have been sending women to war to replenish the human stock without guaranteeing their safe return" Sai (n.d).

The above quotation sums up the approach of many a society and country towards addressing the tragic event of maternal mortality for a greater part of human history. In fact, some researchers prefer using the term neglected tragedy to describe the seriousness of maternal mortality and the attitude of leadership and society in tackling it (Senah, 2003).

According to Senah (2003), maternal mortality was given little attention until the late 1980s when Rasenfield Allan and Deborah Maine drew the attention of the world to that tragedy with their ground breaking article: Maternal Mortality, a neglected tragedy: where is the $M$ in $\mathrm{MCH}$ ? Since then, there have been efforts from world bodies such as the United Nations (UN), Non-governmental organizations, philanthropists, research institutions and individual researchers to find answers to the question of why women "are allowed to die". Arguably, if there has ever been one health issue that has attracted global consensus and witnessed massive investments over the past couple of decades, then it is probably the death of mothers and their children (Partnership for Maternal, Newborn and Child Health, 2011).

The health of women and children has become established as one of the most important indicators for measuring a country's level of development as evidenced by the Millennium Development Goals (MDGs). The high rate of maternal deaths indicates a number of possibilities; high female illiteracy, high poverty rates, ill-equipped health facilities, lack of effective leadership, inter alia. We think, therefore that it is not surprising to find maternal and child health and related issues taking a centre stage in the MDGs. The World Health Organisation [WHO] (2005) for instance explains that the well-being of societies is directly linked to the health and survival of mothers and children. When mothers survive and thrive, their children survive and thrive. When both mothers and children survive and thrive, the societies in which they live prosper.

The WHO (2005), defines maternal death as “... the death of a woman while pregnant or within 42 days of termination of pregnancy, irrespective of the duration and site of the pregnancy, from any cause related to or aggravated by the pregnancy or its management but not from accidental or incidental causes". Complications during pregnancy and childbirth are considered the leading cause of death and disability among women of reproductive age in developing countries. The burden of maternal mortality is traditionally measured in terms of the Maternal Mortality Ratio (MMR), which is defined as the number of maternal deaths per 100,000 live births. MDG-5 calls for a 75 percent reduction in the MMR between 1990 and 2015 (UNDP, 2003). Estimates of the MMR in Ghana vary widely.

According a Ghana MDG Report (2015) between 1990 and 2013, maternal mortality reduced from 760 to 380 maternal deaths per 100,000 live births. It is a significant achievement to 
have halved the MMR. According to projections based on current trends, maternal mortality in Ghana would be 358 deaths per 100,00o live births in 2015. However, this would still be considerably higher than the MMR of 190 deaths per 100,000 live births implied by the MDG 5.1 target (NDPC \& UN, 2015).

On the trend of maternal mortality globally, the WHO (2014) reports that, the total number of maternal deaths decreased by $4 \%$ from 523000 in 1990 to 289000 in 2013. Similarly, global MMR declined by $4 \%$ from 380 maternal deaths per 100 ooo live births in 1990 to 210 in 2013 yielding an average annual decline of $2.6 \%$. Worldwide MMR declined annually by $3.3 \%$ between 2005 and 2013, faster than the 2.2\% average annual decline observed between 1990 and 2005. The world might be making progress in tackling the problem but many a nation especially the developing countries in Africa and Asia still need a lot of efforts.

The definitions of maternal mortality allow identification of maternal deaths, based on their causes, as either direct or indirect (WHO, 2012). Direct maternal deaths are those resulting from obstetric complications of the pregnant state (pregnancy, delivery and postpartum), interventions, omissions, and incorrect treatment. Deaths due to, for example, obstetric haemorrhage or hypertensive disorders in pregnancy, or those due to complications of anaesthesia or caesarean section are classified as direct maternal deaths. Of the deaths due to direct complications related to labor and delivery, postpartum haemorrhage (PPH) accounted for the highest, followed by eclampsia in most studies. Senah (2003) further identified other conditions that cause maternal morbidity or mortality which include ectopic pregnancy, renal failure and cardiac disorders. It is widely believed that some of the conditions mentioned can be predicted while most of them can be prevented or managed if the right conditions prevail. These conditions sometimes interact with the socio-cultural environment to override the right conditions.

There are also indirect or non-clinical causes of maternal mortality (Senah, 2003; ESCAP, 2008; WHO, 2012; Ronsmans \& Graham, 2006). These indirect causes account for approximately $20 \%$ of maternal deaths (ESCAP, 2008). The indirect obstetric causes are preexisting conditions that are exacerbated by pregnancy or its management. Some of these conditions are relative, or absolute contra-indications for pregnancy. Galaa and Daari (2008) identified issues relating to maternal health care as high fertility rate, unsafe abortion and harmful traditional practices as major underlying causes of maternal mortality.

Thaddeus and Maine (1994) have isolated the "Three Delays Model" which explains delays in seeking, reaching, and receiving care as the key factors contributing to maternal death. The delay in seeking care is related to having the knowledge to recognize a life-threatening problem and making the decision to go for care. The delay in reaching care results from inaccessibility of health services due to distance, poor infrastructure, lack of money, or other barriers to access. The delay in receiving care refers to problems in content and quality of maternal health care services. 
If all the road maps to improving maternal health as outlined by the numerous conferences from the 1980 s through the 1990 s to date were implemented to the letter, perhaps maternal mortality could be seen as tragic-comedy. The world also claims to have identified the possible causes of maternal mortality and other factors that may conduce to that tragedy and yet it is still struggling to find solutions to these very problems especially in subSaharan African countries where poverty and disease continue to derail gains made so far (Vaah, 2010).

Available statistics show that the overall trend of maternal mortality rates is declining especially among most developing countries, albeit at a slow rate (WHO, 2014). However, institutional mortality rates continue to rise and although most of the health institutions may attribute this trend to a spillover from communities, there are still reported cases of institutional bottlenecks that hinder the preparedness of those institutions to handle complications related to pregnancies and deliveries. The WHO asserts that for each woman who succumbs to maternal death, many more will suffer injuries, infections, and disabilities brought about by pregnancy or childbirth complications, such as obstetric fistula (WHO, 2005).

Ghana was committed to achieving the MDG 5 and had been giving special attention to reducing maternal mortality in health facilities over the past two decades (GHS, 2009, NDPC\& UN, 2015). Policies designed and implemented to address maternal health problems include free maternal care programme and National Health Insurance Scheme (NHIS), which has resulted in an increase in access and utilization of health services; Comprehensive Abortion Care (CAC); Adolescent Sexual Reproductive Health Services, Focused Antenatal Care; policy direction on the use of Misotac for the prevention and management of Postpartum Hemorrhage ( $\mathrm{PPH}$ ); training in the management and use of uterotonics, training of midwives in life saving skills and the establishment of Prevention of Mother to Child Transmission (РMTCT) centres and services (GHS, 2005, NDPC \&UN, 2015).

Few studies (Senah, 2003; WHO, 2005; Lule et al, 2005; Vaah, 2010) have focused on the medical and socio-economic factors that cause maternal mortality. Thus, it is difficult to find studies which examine socio-cultural factors that predispose women of reproductive ages to the risk of death while pregnant or after delivery. Previous studies have either examined the medical explanatory model in isolation or mention the socio-cultural factors in passing (See: Gumanga et al, 2011; Yego et al, 2013; Agan et al, 2010). The lack of an integrated approach in examining the numerous factors that conduce to the death of mothers is an issue this paper attempts to address.

Although Ghana has made some gains in its fight against maternal mortality the MMR is still high. While maternal mortality figures vary widely by source and are highly controversial, the best estimates for Ghana suggest that roughly 380 will die out of every 100 , ooo live births and higher in relatively rural regions (WHO, 2014). Justifications to fight against maternal mortality have often emanated from the fact that all women, especially mothers 
have a fundamental right to life (Freedman et al., 2005) and as such all efforts must be put in place to ensure the survival of those who attempt to bring forth children. A direct relationship between the health of mothers and their children especially children under five years, has also been established (WHO, 2005; Freedman et al, 2005; Lule et al, 2005). The health of infants and older children has a direct relationship with the health of their mothers (WHO, 2005). Ensuring the survival and good health of mothers will in effect, address the many issues affecting the health of children. Furthermore, Lule et al. (2005) identified the jeopardisation of the economic and social welfare of families and communities as another area where the effects of maternal deaths are felt. According to Lule et al (2005), women are generally the ones that fulfill the unpaid reproductive roles in the family and the home. Early pregnancies, poor maternal and reproductive health and pregnancy complications affect a woman's ability to fulfill these roles. In addition, morbidity and mortality will affect a woman's ability to earn an income, and would contribute to a decline in family's economic status (Lule et al., 2005). Maternal health has therefore become a yardstick for measuring the level of a country's development and a well-functioning health system (Penn-Kekana and Blaauw, 2002).

A review of literature on the trends of institutional maternal mortality revealed three compelling studies conducted in Ghana (at the Tamale Teaching Hospital by Gumanga et al., 2011), Kenya (at the Moi Teaching and Referral Hospital by Yego et al. 2013) and Nigeria (at the University of Calabar Teaching Hospital by Agan et al. 2010). These studies used teaching and referral hospitals as their setting. These Teaching Hospitals in general provide clinical education and training to future and current doctors, nurses and other health professionals, in addition to delivering high quality medical care to patients. These hospitals may also have a commitment to research and are centres for experimental, innovative and technically sophisticated services. Although the current study has similar thematic issues to the aforementioned research studies, it moves the setting from the Teaching Hospital to a Regional Hospital in a relatively rural setting (and serves the poorest population in the country) which is general and broader in scope. The justification for the choice of the hospital is to give credence or otherwise to reports that there is an increasing rate of institutional maternal mortality, although the overall maternal death rates have seen some decline since 1990 (WHO, 2014).

This study undertakes a comprehensive Maternal Mortality Audit at the Wa Regional Hospital in order to discover the trends and identify the causes of maternal mortality at the hospital, and suggests ways of improving the situation. 


\section{Methods}

\section{Study Site}

The Upper West Regional Hospital located in Wa, the regional capital, was established in1919 and later became a district hospital. In 1985, three years after the creation of the Upper West Region, it became known as the Wa Regional Hospital taking on a regional hospital status in the region's capital.

As at 2014, the hospital has 36 departments and wards; among these are administration, Out Patients Department (OPD), Psychiatry, theatre, mortuary and security. The size of its human resource is 308, consisting of a gynaecologist, 41 midwives, 3 physiotherapists, 5 medical officers and 3 pharmacists. The Hospital serves as a referral centre for cases not only from the region but also peripheral towns in Burkina Faso and the Northern and Upper East Regions. It records an average of 8500 cases per month and up to 102,00o cases annually at the Out Patient Department (OPD) (Wa Regional Hospital OPD Records, 2014). Among the cases reported at the OPD, malaria is one of the 10 top reported cases in addition to acute eye infection, gynaecological conditions, anaemia, road traffic accidents, hepatitis, among others (Wa Regional Hospital OPD Records, 2014).

\section{Study Design}

The study employed a retrospective audit of 73 maternal mortality cases at the Wa Regional Hospital from January 1, 2005 to December 31, 2010. It included all pregnancy related deaths at the hospital that occurred for the period. It was an in-depth review of all pre and post pregnancy related deaths recorded in the reports and folders at the hospital within the sixyear time-frame.

In addition to the examination of records, 10 midwives and a gynaecologist at the Maternal Health Department (including antenatal care centre, labour, lying-in and gynaecological wards) were interviewed to assist in shedding some light to the cases and related issues. These respondents clarified information gleaned from patient folders and other records regarding the cases selected. They also provided their perspectives on issues relating to maternal mortality at the hospitals in particular and the region as a whole.

Two data collection instruments were used. An interview guide was used to elicit information from the gynaecologist and midwives, whilst a specially designed information fact sheet was used to extract secondary data. The fact sheet was used to extract information from patient folders, OPD records, and other records needed for the audit. The information fact sheet provided data on maternal deaths, cause of deaths, age of mothers, antenatal attendance, among others.

The reviewed data included socio demographic characteristics of the women who died the main causes of death, pattern of health-seeking behavior for antenatal care / delivery as well 
as socio cultural causes of maternal death in hospital, and duration of hospital stay before death.

\section{Results}

\section{Demographic Characteristics of Maternal Mortality Cases}

The demographic characteristics of the cases gleaned include, age, numbers of previous births, educational attainment, marital status and place of residence. The following presents the results of these variables.

Table 1: Age and birth distribution of cases

\begin{tabular}{|c|c|c|c|c|c|}
\hline \multicolumn{6}{|c|}{ Age Number of Previous Births } \\
\hline & 1 & $2-4$ & $5-9$ & Total & Percentage \\
\hline $15-19$ & 6 & 3 & o & 9 & 12.3 \\
\hline $20-24$ & 7 & 5 & $\mathrm{o}$ & 12 & 16.4 \\
\hline $25-29$ & 5 & 9 & 1 & 15 & 20.5 \\
\hline $30-34$ & 0 & 10 & 7 & 17 & 23.4 \\
\hline $35-39$ & 1 & 8 & 9 & 18 & 24.7 \\
\hline 40 and above & $\mathrm{O}$ & o & 2 & 2 & 2.7 \\
\hline Total & 19 & 35 & 19 & 73 & 100.0 \\
\hline
\end{tabular}

Source: Field Data, July 2013

Table 1 presents the age distribution of cases together with their previous birth history. The results indicate that women aged forty years and above represent the least number of cases among the total deaths with only $2.7 \%$. The age group with the highest number of deaths was 30 to 35 with 24.7 percent, followed closely by the 30-34 age groups with 23.4 percent. Indeed, the age group of 30-39 accounted for nearly half of the deaths in the cases. The remaining age groups had deaths cases as follows, 15-19; 12.3\%, 20-24 16.4\% and 25-29, $20.5 \%$.

The 30-39 age groups accounted for the highest number of deaths due to the fact that they were 'multi-gravid', thus they had given births multiple times in the past. This may result in weakened uterus and hence mortality. The first time mothers were still 'primer-gravid' hence they had a relatively low mortality rate.

The active reproductive age group of 20 to 39 saw the highest incidence of mortality of about $85 \%$ of all the cases. This means that although women younger than 20 and older than 40 are at a risk of dying during child birth, those who fall between the ages of 20 and 39 actually have the greatest risk. This is because they fall in the age bracket where they are likely to get pregnant on several occasions thus increasing their vulnerability. 


\section{Educational Attainment}

Another demographic variable presented was the educational attainment of the women who had died. The data for this variable could only be obtained from folders of non-referred cases since those of referred cases could not be seen. Hence only 36 folders contained details of educational accomplishments and it is presented as follows: Fourteen of them had no formal education at all, 9 had primary level education, 10 had secondary education and 3 had tertiary education. The educational attainment is important because it has implications on health seeking behaviour and antenatal attendance.

\section{Marital Status}

In addition to age distribution, the marital status of the women was also examined. From the data, $89 \%$ of cases were married, while only $11 \%$ were single. Further analysis revealed that this may not necessarily be the case. This is because it was reported that in some instances, parents and relatives of unmarried pregnant women allowed their daughters and female relatives to use their names so as to avoid stigmatization and embarrassment that is usually associated with pregnancy out of wedlock. However, the exact number of such cases could not be readily ascertained.

\section{Place of Residence}

Considering the fact that the Wa Regional Hospital receives referral cases, the research made an attempt to establish the place of residence of the various cases reported to the hospital and how that could have influenced the death of those women.

Table 2: Place of residence

\begin{tabular}{|l|l|l|}
\hline Residence & Frequency & Percentage \\
\hline Wa Municipality & 36 & 49 \\
\hline Rest of the Region & 24 & 33 \\
\hline Northern Region & 9 & 12 \\
\hline Burkina Faso & 4 & 6 \\
\hline Total & 73 & 100 \\
\hline
\end{tabular}

Source: Field Data, July 2013

From Table 2, it can be seen that 49 percent of the cases originated from the Wa Municipal area. The remaining $51 \%$ came from other places. Thirty-three percent of the cases came from towns and villages within the region, whilst $12 \%$ came from the Northern Region, with about $6 \%$ coming from Burkina Faso. More specifically, the referrals from the Northern Region came from towns like, Tuna, Bole and Kulmasa. Other towns from within the region that referred pregnant women to the hospital include, Nadowli, Kaleo, Jirapa, Nandom and 
Lawra. The high percentage of cases from the Wa Municipality is due to the fact that the Regional hospital also serves as the Municipal hospital which is supposed to handle all cases specific to the municipality.

\section{Maternal Mortality Trends}

A review of cases during the study period showed a total of 73 maternal deaths occurred out of 14027 live births, giving a maternal mortality ratio of 520.4 per 100,000 live births.

Table 3: Annual trends in maternal mortality ratio

\begin{tabular}{|l|l|l|l|l|}
\hline Year & Total deliveries & Live births & Maternal deaths & MMR per 10o,ooo live births \\
\hline 2005 & 2260 & 2113 & 6 & 284 \\
\hline 2006 & 1918 & 1867 & 11 & 589.2 \\
\hline 2007 & 2284 & 2133 & 9 & 421.9 \\
\hline 2008 & 2803 & 2651 & 8 & 301.8 \\
\hline 2009 & 2680 & 2515 & 24 & 954.3 \\
\hline 2010 & 2908 & 2748 & 15 & 545.9 \\
\hline Total & 14853 & 14027 & 73 & 520.4 \\
\hline
\end{tabular}

Source: Field Data, July 2013.

The maternal mortality ratio's reduced annually by $49 \%$ from 589.2 per 100,000 live births for the year 2006 to 301.8 per 100,000 live births for the year 2008 after it had increased by $52 \%$ from 284 per 100,000 live births for the year 2005 to 589.2 per 100 , ooo live births for the year 2006. It hit the worse in 2009 at 954.3 per 100,000 live births and reduced again to 545.9 per 100,000 in 2010 representing a $43 \%$ reduction. The most possible reason for the sharp increase in maternal mortality figures in 2009 was attributable to a decentralized antenatal attendance policy where clients were to access these services at designated facilities at the district and sub-district levels other than the regional or central facilities. According to the respondents, most pregnant women were not familiar with the new system and as a result refused to go for antennal visits. Antenatal attendance in that year witnessed appreciable decrease and many women eventually came back to the regional hospitals only when they had serious complications with their pregnancies. These complications mostly led to the death of these pregnant women. Considering this setback, the policy was relaxed and pregnant women could then access their antenatal services from the regional hospital.

\section{Antenatal care, Referred and Non referred Cases and Period of Death}

This section examines data on antenatal attendance and educational level, cases referred or not and period of death. The results are shown in Tables 4 and 5. 
Data on the health seeking pattern for antenatal care, among referred and non-referred cases and periods of death revealed that $72.6 \%$ of the cases attended antenatal care whilst $27.4 \%$ never did. However, a large number of women (75.5 \%) who attended antenatal made only one out of the accepted least number of four visits. Only $13.8 \%$ of patients out of the 53 visited the facility on three or more occasions.

Table 4: Antenatal care, status of cases and period of death

\begin{tabular}{|l|l|l|}
\hline Antenatal visits & Frequency & Percentage \\
\hline Yes & 53 & 72.6 \\
\hline No & 20 & 27.4 \\
\hline Total & 73 & 100 \\
\hline Status of case & & \\
\hline Referred & 37 & 50.7 \\
\hline Non referred & 36 & 49.3 \\
\hline Total & 73 & 100 \\
\hline Period of death & 41 & \\
\hline Pre/ante partum & 32 & 56.2 \\
\hline Post-partum & 73 & 43.8 \\
\hline Total & & 100 \\
\hline
\end{tabular}

Source: Field Data, July 2013

Out of the cases, $49.3 \%$ were cases primarily from the hospital, that is, non-referred whilst $50.7 \%$ were referred cases with 2009 alone having $27.6 \%$ referred cases. The reason for death among the referred cases are attributable to late referral due to late reporting to centres, poor road network and transportation challenges. Additionally, the personnel at the districts and sub-districts usually lacked certain skills and competencies possessed by the colleagues at the regional hospital. This is made worse by poor and inadequate equipment at the local health centres (GHS, 2011). A combination of these factors made the situation dire. Complacency on the part of pregnant women in seeking early attention, delays at the hospital, and other pregnancy complications were reasons that were cited for deaths among the non-referred cases.

On the period of death, the data revealed that death during pre or ante partum was higher (56\%) than post-partum (44\%). This means that more women died before and during childbirth than they did after childbirth. 


\section{Causes of Maternal Mortality at the Wa Regional Hospital}

Another objective of this study was to find out the main causes of these audited maternal deaths that occurred over the period. Since they were deaths occurring in the medical outfit, the medical causes of deaths were determinable and in the 73 cases examined, these causes were noted. The causes have been grouped into direct and indirect. Table 5 shows the details.

Table 5: Causes of maternal deaths at the hospital (Diagnosed Causes)

\begin{tabular}{|l|l|l|l|l|l|l|l|l|}
\hline Causes & Year & $\mathbf{2 0 0 5}$ & $\mathbf{2 0 0 6}$ & $\mathbf{2 0 0 7}$ & $\mathbf{2 0 0 8}$ & $\mathbf{2 0 0 9}$ & $\mathbf{2 0 1 0}$ & Total \\
\hline Haemorrhage & & 2 & 1 & 1 & 2 & 5 & 3 & 14 \\
\hline Eclampsia & & 1 & 2 & 1 & 2 & 3 & 2 & 11 \\
\hline Sepsis & & 1 & 1 & 1 & 1 & 3 & 1 & 8 \\
\hline Obstructed labour & & 0 & 0 & 1 & 2 & 1 & 1 & 5 \\
\hline Unsafe abortion & & 0 & 1 & 1 & 2 & 1 & 1 & 6 \\
\hline $\begin{array}{l}\text { Medical conditions } \\
\text { (malaria et al.) }\end{array}$ & & 2 & 1 & 2 & 1 & 7 & 2 & 15 \\
\hline Others & & 1 & 1 & 1 & 2 & 5 & 4 & 14 \\
\hline
\end{tabular}

Source: Field Data; July2013

The 73 audited maternal deaths in the study period were as a result of direct and indirect causes, with $60 \%$ being from direct causes whilst $40 \%$ from indirect causes. Among the direct causes haemorrhage accounted for $19.2 \%$ of the deaths closely followed by eclampsia, 15.2\%. Sepsis cases represented $11.1 \%$ with obstructed labour taking up $7.1 \%$ and abortion $8.2 \%$. Already existing ailments that were triggered during the pregnancy including malaria, anaemia, HIV/AIDS, hepatitis, CSM and TB accounted for $20.2 \%$ of these deaths whilst cardiac arrest, hypovoleamic shock, thyroid toxocosis, organ failure, heart attack and other related complications accounted for the remaining $19.8 \%$.

\section{Related Non-Medical Causes}

In addition to the above diagnosed causes of deaths, the study sought to identify a number of socio-cultural factors which played significant roles in the 73 deaths. The following factors were gleaned from comments by midwives, nurses and the medical officer at the facility. These were seen as broad non-medical socio-cultural causes which were largely contributory factors other than main causes.

The key informants reported that an indirect cause of maternal death was the pressure to outdo rivals in childbirth in polygamous homes. This resulted in women having multiple pregnancies without consideration to their safety. The indiscriminate use of herbal intoxication - mansugo, the belief in 'spiritual interference' hence women hiding 
pregnancies, seeking permission from deity before women would be sent to health facilities for delivery, among others.

On interference of traditional heads when there are complications, a midwife recounted in one of the cases under review that;

"a spiritual head was called upon by the family of the woman in labour to come and deliver her of a complication when the baby was coming out with its legs, the women had various serious tears in her womb and she eventually bled till she died".

Another socio-cultural cause is the prestige associated with having many children which eventually weakens the uterus. Another is the belief that menopause is the only 'morally accepted' birth control method, the insistence of delivery at home to prove that one was a faithful wife (a check for adultery) as well as being strong. Prominent amongst these are the belief in food taboos, the frowning upon blood transfusion and ultimately poverty, forcing domiciliary deliveries.

\section{Discussion}

The maternal mortality ratio over the period was 520.4 per 100,000 live births, or 73 deaths. Even though this appears to be significantly lower than figures from other studies, it is quite worrisome in view of how far away it is from the MDG target of 185 per 100,000 by 2015 . This finding however, corroborates, the high figures from similar studies. For instance, in a similar study conducted by Gumanga et al., (2011) at the Tamale Teaching Hospital, over a 5 year period, that is, from 2006-2010, the maternal mortality ratio was 1018.7, per 100,000 live births, or a total of 280 deaths.

Studies in two teaching hospitals in Kenya and Nigeria also found similar results. In the case of the Nigerian Teaching Hospital, Agan et al. (2011), using a ten year period, from 1999-2009, found that 231 death occurred giving a maternal mortality ratio of 1513.4 per 1,0,ooo live births. In the Kenyan study, Yego et al. (2013), found that between 2004 and 2011, a total of 150 deaths with an overall maternal mortality ratio of 426 per 100, ooo live births.

In terms of the yearly ratios, our findings reveal an undulating scenario. Thus, there were instances of reductions, increases and reductions again. For instance, the figure rose from 2005 to 2006 (49\%), dropped steadily from 2006 to 2008 (48\%), rose again this time steeply from 2008 to 2009 (52\%) and finally dropped sharply from 2009 to 2010 (43\%). By the end of 2010, the maternal mortality ratio was 545.9 per 100,000. This shows an increase of about $48 \%$ over the 2005 figure. Rather than a steady decline, the maternal mortality ratio was increasing over the years, a clear case of one step forward, and two step backwards. What factors accounts for this unstable nature? 
The major causes of the alarming rates of increase and a relatively small rate of reduction have been attributed to multiple factors (Ensor \& Cooper, 2004).The most compelling reasons for the high number of maternal deaths in the region (Sub Saharan Africa) as a whole and at hospitals in particular include socio-cultural beliefs and practices which pose major barriers to women's health, the low level of awareness about health and danger signs of pregnancy, weak health systems exacerbated by continuing challenges in training and retaining the requisite human resource for health, the lack of access to basic package of health care by many, the large burden of endemic diseases and the challenge of malnutrition and poverty (Ensor \& Cooper, 2004; Hatt, Chankova, \& Sulzbach, 2009). These factors coupled with other issues like poor road network, high illiteracy and unemployment rates have been well documented. Many of the key informants repeated most of these factors as major causes of the current situation.

On the specific causes of death, direct causes accounted for $60 \%$, while indirect causes made up the remaining 40\%. This shows a slight variation from the findings of Gumanga et al (2011), where the direct causes were $71 \%$, while the indirect causes were $29 \%$, although the leading causes are direct causes. Medically, haemorrhage was the highest cause of death among the cases audited. It accounted for $19 \%$ of all the deaths that occurred. The other direct medical causes include Eclampsia (15\%), Sepsis 11\%, abortion related difficulties, $8 \%$ and obstructed labour 7\%. Compared to other studies, such as Gumanga et al, (2011), the top 5 medical causes remained the same but with slightly different arrangement. In their study, Sepsis accounted for most of the direct causes of death, followed by hypertensive disorders and then haemorrhage.

Aside the direct medical causes, there were also indirect causes which could be described as existing preconditions or opportunistic ailments which had fatal consequences on pregnancies and childbirths. These include malaria, aneamia, sickle cell, HIV-Aids and TB. Again this finding was consistent with those from earlier studies. The percentage of indirect causes could be explained by the poor quality of antenatal care and sociocultural factors.

Socio-cultural and other non-medical causes of maternal deaths also revealed that, all three types of delays were present in the deaths. Although the data could not produce any specific figures on how many deaths could be attributed to each of the three delays, we can say that Delays in seeking help, late arrival at the hospital, attempt to deliver at home and some inaction at the hospital were all issues that resulted in deaths. Poor nutrition, due to poverty, religious and cultural beliefs as well as cumbersome and ineffective referral system at the lower level of health care contributed significantly to the deaths.

Related to the above is the health seeking behavior of the cases audited. The study revealed that although the majority of cases got some antenatal care, very few of them actually got the minimum of at least four visits. About $27 \%$ could not even make a single antenatal visit. For instance, 10 out of 36 women who were non-referred patients and for whom complete data was available did not make a single antenatal visit. In such situation, one would 
wonder how those women could find out if they had any pre-existing conditions that could impact negatively on their pregnancies. According to Senah (2003:50) in many societies in the country, it is culturally regarded immodest to show early signs of pregnancy until it is visible. Consequently, often the prenatal screening for risk factors is missed. When this happens, safe delivery is more often than not severely compromised.

The study also found that nearly half of the cases were non referred cases while slightly more than half were referred. Thus there were no significant differences between cases that were originally based in the hospital and those that were brought from elsewhere. Other studies have revealed that most maternal mortality cases come from referrals from lower level cases (Gumanga, et al. 2011, Agan, et al. 2010). The reason for the numbers of death from referred cases was the delay in seeking care, poor transportation and general lack of equipment and skilled personnel at the various sub-centres. Therefore patients are transferred at 'critical moments' where they die less than 3 three days after referral. This questions the referrals regime, the way they are handled at the lower level facility and in transit to the higher level facility.

On time of death, about $56 \%$ of the cases were pre and ante partum that is deaths before and during delivery. The remaining $44 \%$, died after the delivery, or postpartum. This shows that it is very critical for women to receive emergency obstetric care especially 12 hours before and after delivery. This finding was also consistent with the results of Ghana Maternal Health Survey (2007), carried out by the Ghana Health Service, which indicated that the majority of deaths occurred during delivery because of the absence of emergency obstetric and neonatal care $(\mathrm{EmONC})$.

\section{Conclusion}

Even though the trends of maternal mortality in the Upper West Regional Hospital over the period have seen a decline, the decline is not rapid or steep enough to be able to meet the targets of the MDG 5. Despite several efforts to curb this trend the number of women who die from childbirth is still high.

There are a number of medical and non-medical, direct and indirect causes that account for the maternal deaths in the region. Most of these deaths are preventable or in the least can be better managed. The medical and socio-cultural causes must be viewed side by side because they are significantly related. A critical issue that must be given significant attention is the mix of medical and non-medical causes. Further studies should be carried out to determine the exact relationship between the two and how they play out in the maternal mortality situation in the country. 


\section{Recommendations}

The following recommendations and suggestions are offered to help curb the horrifying maternal mortality situation at the hospital and the nation at large. The government and all stakeholders should:

- Improve emergency obstetric care by ensuring that there are enough personnel, logistics and facilities to attend to women who are in labour, especially 12 hours prior to delivery and after delivery. That is, skilled attendance at birth should be a number one priority for all pregnant women in both urban and rural areas.

- Encourage and ensure that a lot more women have access to and actually attend antenatal clinics. This would allow for the preempting of pregnancy related complications and also ensure that pregnant women engage in practices suitable for their condition throughout that period and during delivery.

- Embark upon massive education to reduce negative socio-cultural practices on maternal care.

\section{References}

Agan, T.U., Archibong, E.I., Ekabua, J.E., Ekanem, E.I., Abeshi, S.E., Edentekhe, T.A. and Bassey, E.E. (2010).Trends in maternal mortality at the University of Calabar Teaching Hospital, Nigeria, 1999-2009. International Journal of Women's Health, 2, pp. 249-254.

Ensor, T. and Cooper S. (2004). Overcoming barriers to health service access: influencing the demand side. Health Policy Planning 19: pp. 69-79.

ESCAP (2008). Reduction of maternal mortality. A Joint WHO/UNFPA/World Bank Statement. WHO: Geneva.

Freedman, L.P. et al. (2005). Who's got the power?: transforming health systems for women and Children, London: Earthscan.

Galaa, S. Z. and Daare, K. (2008). Understanding barriers to maternal and child health services utilisation in Northern Ghana. Journal of Social Development in Africa, 23 (2), pp. 127-155.

Ghana Health Service (2012). Annual health sector report, 2011. Ghana Health Service, Accra, Ghana.

Ghana Health Service (2009). In-depth review of the community-based health planning services (CHPS) programme: A report of the Annual Health Sector Review. School of Public Health, Accra, Ghana. 
Ghana Health Service Annual Report (2005). Reproductive and Child Health Unit, Public Health Unit, Ghana.

Ghana Statistical Service, Ghana Health Service and ICF Macro (2009). Ghana Demographic and Health Survey 2008: Key Findings. Maryland: ICF Macro.

Gumanga, S.K. Kolbila, D.Z. Gandau, B.B.N., Munkaila, A., Malechi, H. and KyeiAboagye, K. (2011).Trends in maternal mortality in tamale teaching hospital, Ghana. Ghana Medical Journal, 45 (3), pp. 105-110.

Hatt, L., Chankova, S. and Sulzbach, s. (2009). Maternal health in Ghana: investigating the impact of the National Health Insurance Scheme on maternal health indicators. USAID, Health Systems 20/20. Available: www.healthsystems2020.org

Lule, E., Ramana, G.N.V., Oomman, N., Epp, J., Huntington, D. and Rosen, J.E. (2005). Achieving the Millennium Development Goal of improving maternal health: determinants, interventions and challenges. Health, Nutrition and Population (HNP) Discussion Paper, World Bank, Washington.

Ministry of Health (2008). Ghana Maternal Health Survey 2007, Accra, Ghana.

National Development Planning Commission (2015). Ghana Millennium Development Goals 2015 Report. Accra: NDPC.

Penn-Kekana, L. and Blaauw, D. (2002). A rapid appraisal of maternal health services in South Africa: a health systems approach, Centre for Health Policy, University of the Witwatersrand, South Africa.

Ronsmans, C. and Graham, w. J. (2006). Maternal mortality: who, when, where, and why. Lancet, 368, 1189-200.

Senah, A. (2003). Maternal mortality in Ghana: the other side. Research Review NS 19 (1), pp. 47-55

Thaddeus, S. and Maine, D. (1994). Too far to walk: maternal mortality in context. Social Science and Medicine 38(8), pp.1091-1110.

The Partnership for Maternal, Newborn and child Health (2011). A Global review of the key interventions related to reproductive, maternal, newborn and child health (RMNCH). Geneva, Switzerland: PMNCH.

United Nations Development Programme (2003). Human development report 2003Millennium Development Goals: A compact among nations to end human poverty. New York: UNDP.

Vaah, E. (2010). Reducing maternal and neonatal mortality in Ghana, role of quality of care at delivery, Health Platform Forum Midweek. 
Wa Regional Hospital (2014). Out-patient department records. Biostatistics Unit

WHO (2005). World Health Report 2005: Make every mother and child count. Geneva: World Health Organization.

WHO (2012). Trends in maternal mortality: 1990 to 2010, Geneva, Switzerland.

\section{http://www.whqlibdoc.who.int/publications/2010/9789241500265_eng.pdf Accessed in April 2013.}

WHO (2013). Closing the health equity gap: policy options and opportunities for action. World Health Organization, Geneva: Switzerland.

WHO (2014). Trends in maternal mortality: 1990 to 2013: Estimates by WHO, UNICEF, UNFPA, World Bank and United Nations Population Division, Geneva: WHO.

Yego, F., Williams, J.S., Byles, J., Nyongesa, P., Aruasa, W. and D'Este, C. (2013). A retrospective analysis of maternal and neonatal mortality at a teaching and referral hospital in Kenya. Reproductive Health, 10(13), pp.1-8. 